\title{
Spontaneous Ignition of Pressurized Releases of Hydrogen and Natural Gas into Air
}

\author{
Frederick L. Dryer, ${ }^{*}$ Marcos Chaos, Zhenwei Zhao, Jeffrey N. Stein, \\ Jeffrey Y. Alpert, and Christopher J. Homer \\ Mechanical and Aerospace Engineering, Princeton University, Princeton, NJ
}

\begin{abstract}
This paper demonstrates the "spontaneous ignition" (autoignition/inflammation and sustained diffusive combustion) from sudden compressed hydrogen releases that is not well documented in the present literature, for which little fundamental explanation, discussion or research foundation exists, and which is apparently not encompassed in recent formulations of safety codes and standards for piping, storage, and use of high pressure compressed gas systems handling hydrogen. Accidental or intended, rapid failure of a pressure boundary separating sufficiently compressed hydrogen from air can result in multi-dimensional transient flows involving shock formation, reflection, and interactions such that reactant mixtures are rapidly formed and achieve chemical ignition, inflammation, and transition to turbulent jet diffusive combustion, fed by the continuing discharge of hydrogen. Both experiments and simple transient shock theory along with chemical kinetic ignition calculations are used to support interpretation of observations and qualitatively identify controlling gas properties and geometrical parameters. Although the phenomenon is demonstrated for pressurized hydrogen burst disk failures with different internal flow geometries, similar phenomena apparently do not necessarily occur for sudden boundary failures of storage vessel or transmission piping into open air that have no downstream obstruction. However, subsequent reflection of the resulting transient shock from surrounding surfaces through mixing layers of hydrogen and air may have the
\end{abstract}

Received 19 July 2005; accepted 3 January 2006.

This work was supported by discretionary research funds available to Prof. Dryer and by a Mechanical and Aerospace Engineering Department summer research fellowship (J.N.S.). The authors wish to acknowledge Prof. C.K. Law for recommending several references cited in the final manuscript revision.

*Address correspondence to fldryer@princeton.edu 
potential for producing ignition and continuing combustion. Much more experimental and computational work is required to quantitatively determine the envelope of parameter combinations that mitigate or enhance spontaneous ignition characteristics of compressed hydrogen as a result of sudden release, particularly if hydrogen is to become a major energy carrier interfaced with consumer use. Similar considerations for compressed methane, for mixtures of light hydrocarbons and methane (simulating natural gas), and for larger carbon number hydrocarbons show similar autoignition phenomena may occur with highly compressed methane or natural gas, but are unlikely with higher carbon number cases, unless the compressed source and/or surrounding air is sufficiently pre-heated above ambient temperature. Spontaneous ignition of compressed hydrocarbon gases is also generally less likely, given the much lower turbulent blow-off velocity of hydrocarbons in comparison to that for hydrogen.

Keywords: Hydrogen; Ignition; Natural gas; Pressure release; Safety; Shock

\section{INTRODUCTION}

The transmission, storage, and use of compressed flammable gases are integral to the industrial, commercial, and residential fabric of the nation. The compressed flammable gas most familiar to consumers is natural gas. The use of natural gas continues to grow in refining, power generation, fertilizer manufacture, and other industrial processing applications as well as in commercial and residential heating/air-conditioning and food processing. Compressed natural gas also continues to be of interest as a transportation fuel alternative.

Currently, the distribution of natural gas resources within North America is principally by pipelines operating at pressures from 200 to 1500 psi (i.e., 14 to $100 \mathrm{~atm}$, approximately) (NaturalGas.org, 2004). Local storage is typically on the low pressure side of this range, with reduced pressures utilized in local commercial and residential distribution and much lower pressures actually utilized within such facilities. Forecasts suggest that natural gas supply and transport will have to grow substantially to meet a projected need of about 30 trillion cubic feet by the end of this decade (INGAA Foundation, 2004). The general consensus is that the traditional basins that today supply about $80 \%$ of production in the United States and Canada are in decline in both absolute and market share terms. There will be an increasing need to replace both the present producing basins with currently untapped supplies from areas that are generally more remote from the consuming markets in North America. Liquefied Natural Gas (LNG) delivered to large marine terminals will contribute heavily to supplies in the next decade. It is likely that not only will new pipelines be needed to distribute the ever increasing amounts of natural gas needed, but that the average operating pressure 
of pipelines will increase. For example, long-distance transfer pipelines to transport Alaskan natural gas are proposed with design pressures in excess of $140 \mathrm{~atm}(\sim 2000 \mathrm{psi})$ (Transport Canada Prairie and Northern Region, 2003). The interface with consumers in terms of the use of compressed natural gas as a transportation fuel also typically utilizes storage pressures of 140 to $200 \mathrm{~atm}$ ( 2000 to $3000 \mathrm{psi}$ ).

Safety issues involving natural gas at the consumer interface have been extensively studied and are a subject of continuing interest. For example, the search continues for improved odorants that are not removed by soil permeation, and new appliance designs have emerged that cannot ignite spurious liquid flammable vapors accidentally present. In all of these consumer interfaces, the layman has little exposure to the technologies and design criteria underlying their ability to utilize natural gas safely. While the fundamental issues are essentially transparent to the end-user, failure to consider the applied implications can have catastrophic consequences.

The flammable gas that is the principal subject of this paper, hydrogen, also has a long history of importance in the industrial world in chemical processing, inclusive of refining, fertilizer, and chemical synthesis of materials. Compared to natural gas, its use in the commercial and residential sectors is very limited. In the last few years, hydrogen has emerged (again) as a favored energy carrier of the future (Gregory and Pangborn, 1976; Hord, 1978; Fischer, 1986; Kruse et al., 2002; Shinnar, 2003). Interests are principally driven by the global climatological implications of carbon emissions from carboncontaining fuels, the promise of increased efficiency of and zero emissions from Proton Exchange Membrane (PEM) fuel cells, and other issues, including political/societal/strategic hyperbole (Rifkin, 2002). Converting a significant portion of the present energy infrastructure to hydrogen would require increasing the production rate up to ten times the current level, presently on the order of ten million tons annually (Argonne National Laboratory, 2004), and an infrastructure to distribute and locally store hydrogen would need to be developed. While significant research is underway for finding mechanisms to increase the energy density of hydrogen storage, liquefaction and high compression will continue to play major roles in hydrogen distribution and storage. Compressed gas storage at 340-700 atm $(\sim 5000$ $10,000 \mathrm{psi}$ ) is under consideration by the personal transportation industry. It must be assured that safety at the consumer interface with hydrogen be comparable or exceed that present with natural gas use. Many government and professional agencies are presently developing design and product handling standards for the production and transport of hydrogen that encompass use by consumers in residential and transportation applications. 
The potential of unwanted fires and explosions has always been a major focus of concern with hydrogen. The public sensitivity to hydrogen relates (perhaps unfairly) to some historical events such as the Hindenburg disaster in Lakehurst, New Jersey on May 6th, 1937 (Vidicom Media Productions, 2005). The implication of hydrogen in causation of such accidents derives from its ignition and combustion properties which are atypical of flammable hydrocarbons such as methane, ethane, and liquefied petroleum products (e.g., propane, butane). Alcock et al. (2001) recently summarized some of the properties of both hydrogen and methane that are important to fire safety (Tables 1 and 2). The most important points are that the minimum ignition energy of hydrogen is extremely low, its flammability limits are much wider, its flame temperature is somewhat higher, and its reference laminar flame speed is far greater in comparison to the respective properties for gaseous hydrocarbons.

In unconfined, pre-mixed flammable mixtures, slow deflagration can occur. Furthermore, the slow deflagration can be accelerated (e.g., by extreme initial turbulence, turbulence from obstacles, or confinement), and the result will be a transition to a detonation (Berman, 1986; Sidirov and Dorofeev, 1998; Kaltayev et al., 1999). Once initiated, a detonation is self-sustaining (i.e., turbulence or confinement are not required) as long as the combusting mixture is within the detonable range. In comparison to natural gas, the ability of hydrogen to initiate a detonation or to transition from a deflagration to a detonation (deflagration-detonationtransition, DDT) is more likely.

On the other hand, even though hydrogen has a greater propensity to leak than other gaseous flammables (Table 2), it has been argued that should a compressed hydrogen leak occur, the high diffusivity of hydrogen should result in a rapid dispersal of the leak beyond flammability concentrations. Moreover, the energy content of a hydrogen leak is comparably smaller than that of a methane leak for the same volumetric leak rate. On the other hand, the turbulent non-premixed flame properties of hydrogen-air mixtures permit turbulent jet flames to exist at velocities far in excess of those possible with hydrocarbon-air mixtures (Schefer et al., 2004).

Finally, the disparity in minimum ignition energy between hydrogen and gaseous hydrocarbons may not be as significant in terms of hazard issues as it might appear. The minimum ignition energy for hydrogen/air mixtures is at near-stoichiometric conditions, i.e., $29 \%$ (vol) hydrogen in air. However, at the lean flammability limit, the ignition energy requirement is more similar to that of methane, and weak ignition sources such as electrical equipment sparks, electrostatic sparks or sparks from striking objects typically involve more energy than is required to ignite methane and natural gas as well as hydrogen. 
Table 1. Compressed gas properties for hydrogen and methane (Alcock et al., 2001)

\begin{tabular}{lll}
\hline Property* & Hydrogen $\left(\mathrm{H}_{2}\right)$ & Methane $\left(\mathrm{CH}_{4}\right)$ \\
\hline Molecular weight & 2.016 & 16.043 \\
Diffusion coefficient in air at NTP $\left(\mathrm{cm}^{2} / \mathrm{s}\right)$ & 0.61 & 0.16 \\
Viscosity at NTP $\left(\mathrm{g} / \mathrm{cm}-\mathrm{s} \times 10^{-5}\right)$ & 89 & 11.7 \\
Density at NTP $\left(\mathrm{kg} / \mathrm{m}^{3}\right)$ & 0.0838 & 0.6512 \\
Ratio of specific heats, Cp/Cv at NTP & 1.308 & 1.383 \\
Flammability limits (vol. \% in air) & & \\
Lower limit (LFL) & 4 & 5.3 \\
Upper limit (UFL) & 75 & 15 \\
Minimum ignition energy (mJ) & 0.02 & 0.29 \\
Adiabatic Flame Temperature in air (K) & 2318 & 2158 \\
\% Thermal energy radiated from flame & 5 to 10 & 10 to 33 \\
$\quad$ to surroundings* & & \\
Maximum burning velocity (m/s) & 3.46 & 0.43 \\
Concentration at maximum (vol. \%) & 42.5 & 10.2 \\
Burning velocity at stoichiometric (m/s) & 2.37 & 0.42 \\
Concentration at stoichiometric (vol. \%) & 29.5 & 9.5 \\
Detonability limits (vol. \% in air) & & \\
Lower limit (LDL) & $11-18$ & 6.3 \\
Upper limit (UDL) & 59 & 13.5 \\
\hline
\end{tabular}

${ }^{*}$ Normal temperature and pressure are defined as $20^{\circ} \mathrm{C}$ and 1 standard atm pressure.

${ }^{* *}$ Typical values for different flame configurations and combustion efficiencies.

Table 2. Relative leak rates of hydrogen and methane (Alcock et al., 2001)

\begin{tabular}{lcc}
\hline Configuration & Hydrogen $\left(\mathrm{H}_{2}\right)$ & Methane $\left(\mathrm{CH}_{4}\right)$ \\
\hline Relative leak rates (volumetric) & & \\
Subsonic flow & 1 & 0.26 \\
$\quad$ Diffusion & 1 & 0.77 \\
$\quad$ Laminar flow & 1 & 0.35 \\
$\quad$ Turbulent flow & 1 & 0.34 \\
Sonic flow & & \\
Relative leak rates (energy basis*) & & 0.87 \\
Subsonic flow & 1 & 2.66 \\
$\quad$ Diffusion & 1 & 1.18 \\
$\quad$ Laminar flow & 1 & 1.14 \\
$\quad$ Turbulent flow & 1 & \\
\hline
\end{tabular}

*Based on lower heating values. 
Hydrogen flames are also vastly different from hydrocarbon flames in terms of heat transfer characteristics (Table 1). With large scale, diffusively limited burning for hydrocarbon fuels (even methane), soot formation can occur, significantly enhancing radiant heat transfer to surrounding materials. Even without soot formation, hydrocarbon flames remain somewhat visible because of chemiluminescent emissions. On the other hand, a hydrogen flame is almost invisible even though the adiabatic flame temperature is higher. While the thermal radiation emitted from diffusively limited combustion is considerably lower than that from a sooting hydrocarbon flame, inhalation of hot combustion products from hydrogen flames can severely damage lung tissue. Additives to make hydrogen flames luminous and/or that can be used to odorize hydrogen to detect leaks, and yet not impact fuel cell operation, may be difficult to identify.

As a result of the intense interest of hydrogen as an energy carrier, there have been numerous studies initiated, some completed, and others ongoing to refine the understanding of hydrogen safety issues and to embody this knowledge in design and safety codes (e.g., see National Hydrogen and Fuel Cell Codes and Standards Coordinating Committee Website, 2005). It has been said that shut-off safety systems are sufficient to ensure safety in fuel cell cars and hydrogen fueling stations as they would avoid unwanted leaks (California Hydrogen Highway, 2004). This technology is not as amenable to unwanted discharges in pipeline distribution systems or storage vessels. In general, the recent safety evaluations describe hydrogen as "a safer material than gasoline or liquefied petroleum gases" (Thomas, 1997; California Hydrogen Highway, 2004), report that general hydrogen handling and safety concerns have been historically shown to be well in hand (NFPA, 2005), and conclude that educating the public of the safety issues involved specifically with hydrogen is very significant in achieving acceptance of hydrogen in the consumer market (California Hydrogen Highway, 2004; National Hydrogen Association, 2005).

Acknowledging that unwanted discharges can occur in consumer handling situations and that sudden fracture of containers or pipelines can also occur, either in accidents or as subversive acts, a number of efforts have considered the character of flammable plume envelopes generated by hydrogen leaks (Swain, 2004; Schefer et al., 2004; Houf and Schefer, 2004). Clearly, the separation of ignition sources from the region in which flammable mixtures might be produced is generally an effective safety consideration.

However, the literature contains numerous fire accident scenario descriptions in relation to hydrogen releases into air that remain, at best, speculatively understood (Bond, 1991; National Research Council, 1995; Edeskuty and Stewart, 1996), i.e., there was no clearly identifiable 
ignition source. Frequently, hydrogen's low minimum ignition energy and potential catalytic activity are involved in attempting to describe how these accidents occurred. In the course of preparing the final manuscript, an interesting review on this subject was presented in September 2005 by Astbury and Hawksworth (2005).

The present combustion laboratory had such a fire incident in the early 1980s when a pressure relief burst disk in a hydrogen gas supply system ruptured as a result of a regulator failure on a 1-A compressed hydrogen bottle (supply pressure $>40 \mathrm{~atm}$ ). No readily identifiable ignition source was apparent in the vicinity of where the fire occurred, yet the sudden pressure release by the burst disk resulted in a large, turbulent jet diffusion flame, stabilized at the $\left(1 / 4^{\prime \prime}\right.$ stainless steel tube) discharge of the safety system.

Much speculation concerning less obvious ignition sources for hydrogen leaks fills the technical literature. The Joule-Thompson coefficient for hydrogen becomes negative above a relatively low temperature ( 28 to $200 \mathrm{~K}$, depending on pressure) and a constant enthalpy expansion from high pressures under these conditions leads to an increase in gas temperature (Zuttel, 2003). Joule-Thompson heating is typically incapable of significantly raising the temperature of hydrogen. A temperature increase of only about $6 \mathrm{~K}$ occurs over a depressurization from $140 \mathrm{~atm}$ (Compressed Gas Association, 2004). Other suggested ignition sources include static electrical discharge and high velocity particle impact (Edeskuty and Stewart, 1996). The high critical flow velocity accompanying decompression of high pressure hydrogen can also generate static electrical charge triboelectrically. Impact of small particles carried in such as stream could contain sufficient kinetic energy so as to produce ignition by their impact, or perhaps catalytic nature. Edeskuty and Stewart (1996) suggest that total elimination of ignition sources from static electrical and flowing particles is very difficult under field conditions. But the fact that such ignition sources must also be coincident with flammable mixtures for ignition to occur seems to be ignored in many such speculations.

Finally, Edeskuty and Stewart (1996) mention the possibility of shock wave ignition of premixed hydrogen-air mixtures, without further discussion of how premixed mixtures and shock wave interactions might occur. The "diffusion ignition" processes of unmixed flammable gas/air mixtures with subsequent inflammation and turbulent jet combustion have escaped much of the applied fire-safety literature, but appear to have been first studied scientifically by Wolanski and Wojciki (1972). When a compressed hydrogen source is released into a surrounding oxidizer, there is the potential for development of a transient shock wave formation. The resulting temperature of the compressed oxidizer can considerably exceed that of the expanding hydrogen, and if mixing of the hot 
oxidizer and expanding hydrogen is sufficiently fast in contact regions, it is possible to obtain, autoignition, flame spreading through the flammable mixture, and transition to turbulent diffusive burning. Wolanski and Wojciki identified diffusive mixing as the limiting process, and referred to the ignition scenario itself as "diffusive ignition."

Wolanski and Wojciki (1972) demonstrated diffusive ignition by studying the issuance of a hydrogen jet into oxygen. A high pressure hydrogen source was created by using a shock tube apparatus and the high-pressure hydrogen ruptured a second membrane, resulting in the ejection of hydrogen through the side wall of a cylindrical test chamber containing oxygen. A simple diffusion theory was developed to correlate the dependence of the measured ignition delay as a function of the resulting shock wave propagating in oxygen. While the inverse problem was also studied, no demonstration of the phenomenon was performed for other geometries or with air as the oxidizing media. In comments to the paper, Liñán described a high activation energy asymptotic analysis (later published by Liñán and Crespo, 1976), which considered in more depth the possible configurations of the evolving mixing layer separating a flammable gas and oxidizer.

It has recently come to the authors' attention that in studies of flammable cloud formation by pressurized releases of hydrogen or methane jets into air, Chaineaux et al. (1990) noted what they termed "spontaneous ignition" (autoignition/inflammation/sustained turbulent diffusive burning) of a compressed hydrogen release into air. In their experiments, the flammable gas was forced through a small circular hole, in some cases with a short length of tubing attached downstream. They reported that spontaneous ignition occurred in only one experimental configuration repeatedly and only with hydrogen as the test gas. The case was a $\sim 100 \mathrm{~atm}$ hydrogen source discharged through a $12 \mathrm{~mm}$ hole with a $120 \mathrm{~mm}$ length of $15 \mathrm{~mm}$ inside diameter tubing attached downstream of the hole. "Nearly instantaneous" spontaneous ignition occurred after the jet was released, with good repeatability for this configuration. No additional tests of geometrical effects or analyses of the data are reported to further characterize under what conditions spontaneous ignition might occur. Through the remainder of this paper, we will use the term "spontaneous ignition" to refer to autoignition and inflammation leading to sustained turbulent diffusive combustion.

In reviewing the ignition sources possibly involved in the fire accident that this laboratory incurred, one of the present authors (FLD) theorized at the time that the spontaneous ignition event might have been initiated by transient shocks produced by the failure of the burst disk itself. But no reference to the spontaneous ignition problem or designs to avoid the problem were found in the hydrogen storage and plumbing standards. In fact, the most recent hydrogen safety studies and regulations (e.g., 
NFPA 55, 2005) also fail to discuss the potential for the sudden failure of a pressure boundary separating compressed hydrogen and air to cause spontaneous ignition events.

In summary, the data in the literature on spontaneous ignition of compressed hydrogen releases at the time of the present work was relatively sparse. In fact, no experimental work exists on spontaneous ignition of pressurized flammable gas releases (of varying geometries) into an unconfined atmosphere, which would be representative of incidents reported in industry. The present work was undertaken initially as a senior thesis by two of the authors (Alpert and Homer, 2005) to demonstrate spontaneous ignition of hydrogen-air mixtures solely as a result of a sudden, high pressure discharge into air. Further experiments and analyses were subsequently conducted and are reported here, along with additional analyses of the observations. The experiments clearly confirm the importance of compressed gas pressure and temperature as well as geometry on the production of spontaneous ignition in high pressure hydrogen releases into air. Observations have immediate and significant implications on the safety measures and piping/storage codes since the use of high pressures in the transport, storage, and future consumer uses of compressed hydrogen inherently includes this ignition potential, and point to the need for additional research to develop appropriate safety standards.

\section{CONFIRMING EXPERIMENTS}

The principal purpose of the present experiments was to confirm that transient shock formation and mixing associated with failure of a burst disk separating compressed hydrogen and air can cause spontaneous ignition of the escaping hydrogen. A variety of experiments were conducted to investigate the dependence of observations on the failure pressure and internal flow geometry downstream of the disk. Experiments were performed using different open-ended flow geometries downstream of a standard commercial, screw union type, straight-through burst disk holder with $1 / 2^{\prime \prime}$ NPT female connections $(1.83 \mathrm{~cm}$ ID) on both sides of the holder (Figure 1a, Figure 1c). Both commercial and in-housemanufactured burst disks with different failure pressures were used in the experiments. Failure of each burst disk was induced by slowly raising the flammable gas supply pressure to the burst disk failure pressure. For safety reasons, a majority of the experiments, particularly those at failure pressures higher than about $40 \mathrm{~atm}(\sim 600 \mathrm{psia})$ were performed in open air, out of doors. Ambient air temperatures for the experiments ranged between $280 \mathrm{~K}$ and $305 \mathrm{~K}$, with relative humidity levels between 60 and $90 \%$. 


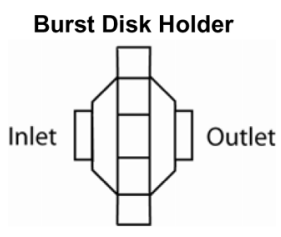

(a)

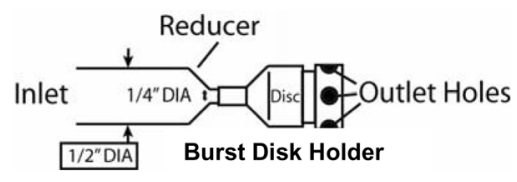

(b)

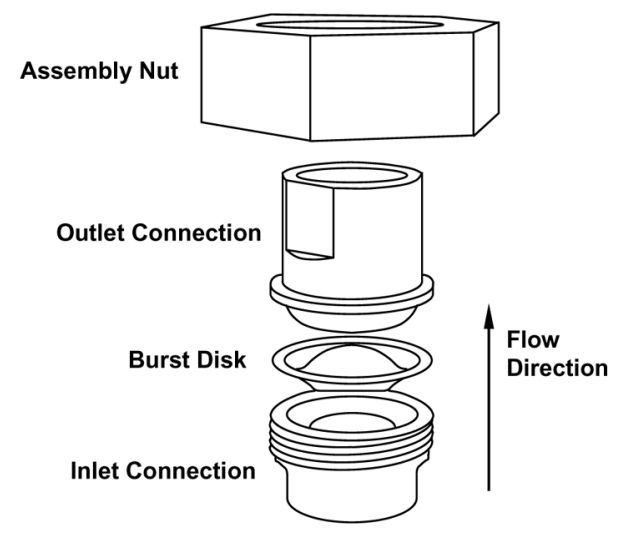

(c)

Figure 1. Burst disk holder styles. (a) Union (screw) holder with $1 / 2^{\prime \prime} \mathrm{NPT}$ female fittings; (b) "T" union (screw) holder with $3 / 8^{\prime \prime}$ NPT inlet, $1 / 4$ " outlets; (c) expanded view of setup shown in (a).

As noted below, flow geometry downstream of the burst disk location was found to strongly influence observations using the straight-through holder, particularly at lower compressed hydrogen pressures. Several experiments were also conducted using commercial burst disks and a " $\mathrm{T}$ " type commercial burst disk holder. The " $\mathrm{T}$ " type unit (Figure 1b) had a 3/8" NPT (1.3 cm ID) entrance and a 90 degree baffle exit with four orthogonally placed exit holes of $6.35 \mathrm{~mm}$ diameter each. No spontaneous ignition events were observed with either compressed hydrogen or natural gas for failure pressures less than $56.6 \mathrm{~atm}$ (81 psig). Additional experiments were not conducted with this burst disk holder design primarily because it was difficult to modify downstream geometry. No experiments with any type of burst disk holder were conducted at failure pressures above $113.2 \mathrm{~atm}$ (1650 psig). The present experiments were also formulated specifically to investigate under what conditions spontaneous ignition might occur. It is probable that local autoignition might have occurred in some experiments, but did not transition to turbulent diffusive burning. Characterization of such 
circumstances would require much more sophisticated, time resolved diagnostics.

A simple apparatus was constructed to study burst disk failure using the straight through holder (Figure 2). Compressed gas pressure was controlled in a system volume upstream of the burst disk using a two stage regulator mounted on a 1-A compressed gas cylinder. The compressed gas cylinder valve and the regulator valve provided redundancy to a supply valve that was used to control compressed gas flow to the system. The system volume upstream of the disk was varied by incorporating stainless steel tanks of different volumes from 2.25 liters to 0.25 liters and/or by using $1 / 2^{\prime \prime}$ NPT stainless steel pipe $(1.83 \mathrm{~cm}$ ID) of varying lengths (as little as $0.30 \mathrm{~m}$ ). Upstream volume had no significant influence on the spontaneous ignition observations, but varied the overall blow-down time subsequent to disk rupture. Essentially the spontaneous ignition process (when it was observed) occurred on very short time scales in comparison with system depressurization times. As noted above, flow geometry downstream of the burst disk holder was varied in the experiments and several tests were repeated for specific configurations. Threaded pipe fittings were assembled with Teflon pipe ribbon, and all fittings were leak checked with soap solution for each configuration prior to each experiment.

Commercial "Type B" aluminum burst disks (Figure 3) manufactured by BS\&B Safety Systems, LLC were used in initial experimentation. The Type B design, developed more than sixty years ago, is a solid metal disk that retains its initial contour during exposure to normal system

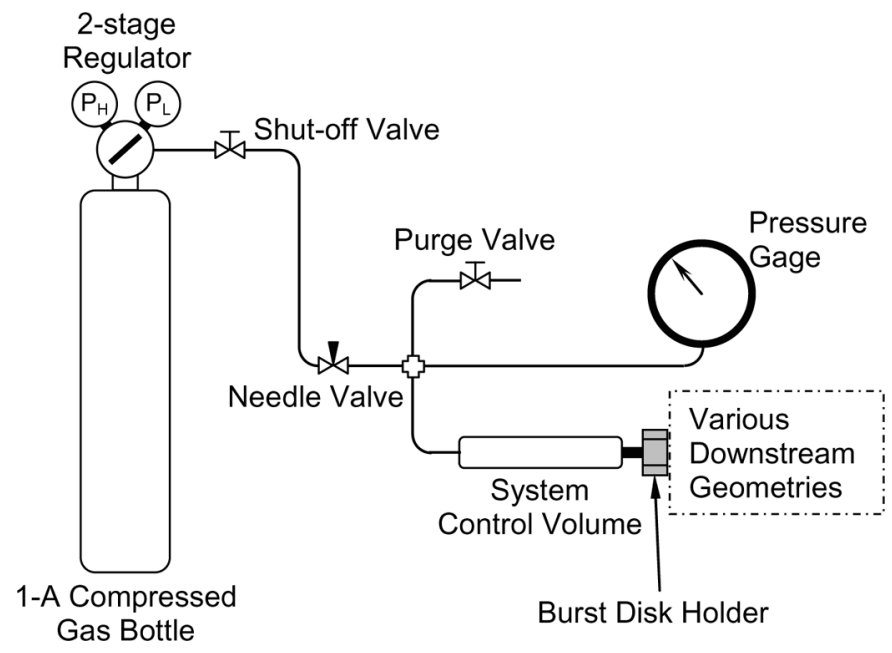

Figure 2. Schematic of experimental configuration. 
pressure differences. The outer collar is form-fit around the union and screw flanges and the inner section of the disk forms a concave "crown" extending downstream in the holder (Figure 1c). The disk material acts as a metal gasket seal when the union flanges are tightened. Thin layers of silicone grease were also applied to the outer edges of the disks to further aid in achieving the seal with the union flanges. An upstream overpressure build-up above the rating of the disk causes a thinning of the metal at the center of the concave crown. Failure then takes place near the center, and the subsequent release of the compressed gas through the holder results in an opening pattern of varying shapes, with "petals" of disk material expanded to the outer diameter of the holder passage. Under most instances, the petals are entirely retained on the remaining disk (Figure 3).

Commercial burst disks are reasonably expensive, and thus Type B burst disks were also manufactured in the laboratory using different thicknesses of aluminum shim stock from 76-229 $\mu \mathrm{m}\left(0.003-0.009^{\prime \prime}\right)$ and a two-step process. Pieces of shim stock were cut to size. Silicone spray was applied to the sized flat shim stock disks, and the disks were then placed in a spare screw union disk holder. The screw union was wrench tightened to form the flat shim stock circumference into the geometrical shape of the commercial disk crown. An aluminum mold was numerically machined to the concave shape of the center of the commercial disk crown, and in a second process step, the shaped shim stock disk was pressed in the mold to obtain the same overall manufactured disk shape as that found for a commercial Type B disk.

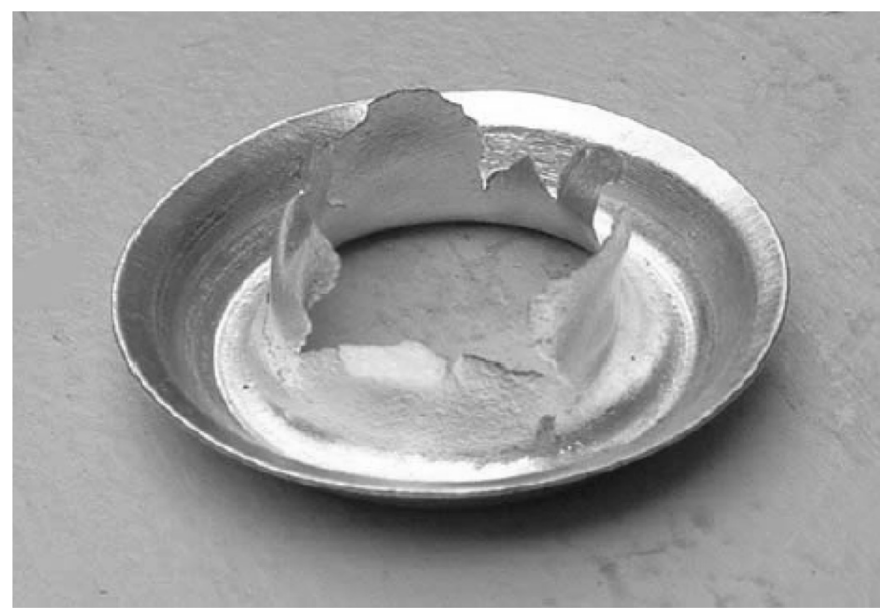

Figure 3. A ruptured Type B burst disk. 
Large changes in the average failure pressure of manufactured disks were obtained by using different shim stock thicknesses. For the thinnest shim stock, small adjustments of failure pressure $(<1.5 \mathrm{~atm})$ were made by modifying the second step and producing small variations in the concave deformation in the center of the crown. The failure pressure from disk to disk for each shim stock and manufacturing method was nearly as repeatable $( \pm 0.3 \mathrm{~atm})$ as the designed failure pressure of commercially manufactured disks. No differences in observations were noted between results obtained with commercial or manufactured disks.

Overall, more than 200 experiments were conducted with hydrogen, the straight-through screw union burst disk holder and various upstream and downstream geometries for failure pressures ranging from $11.2 \mathrm{~atm}$ to $113.25 \mathrm{~atm}$. In each experiment, compressed gas was purged through the entire system upstream of the disk at low pressures $(\sim 1.5 \mathrm{~atm})$, with the burst disk holder screw union fittings only hand-tightened. During the purge event, the burst disk holder screw union fittings were wrench-tightened, and then the purge exhaust valve was closed, leaving the system pressurized. Leak checks of the system were conducted using soap solution and by monitoring the system pressure with the supply valve closed. The supply valve was reopened and the compressed gas system pressure was then slowly raised by increasing the two stage regulator pressure setting manually until the burst disk failed. Alternatively, the regulator pressure was set above the failure pressure, the supply valve was opened, and the rate of system pressure increase was controlled by a needle valve placed in the line just downstream of the supply valve.

In all cases, the system pressure was monitored using calibrated pressure test gages with appropriate pressure scales $(< \pm 0.2 \mathrm{~atm}$ accuracy). Test gage readings at the time of disk rupture were monitored visually in early experiments and, in later experiments, recorded digitally either using a calibrated pressure transducer $(\mathrm{P}<69 \mathrm{~atm}, 1000 \mathrm{psig})$ or a video record of the test gage reading and event. In tests where the pressure was recorded using a pressure transducer, compressed gas temperatures in the system storage volume were also recorded using a small diameter, sheathed thermocouple. Pressurization rates were sufficiently slow that initial compressed gas temperatures never varied from ambient air temperatures by more than $10 \mathrm{~K}$.

The maximum hydrogen flow rate from the regulator to the system volume upstream of the burst disk after burst disk failure was restricted in some of the experiments using a needle valve in the supply line, and in all of the experiments by the $1 / 4^{\prime \prime}$ stainless steel tube flow resistance. The supply valve was closed several seconds after the burst disk failed. The test sequence was then repeated with a new burst disk and the same or a modified downstream flow configuration. 
In early experiments, it was quickly discovered that the flow geometry downstream of the burst disk holder had strong effects on whether and at what minimum burst disk failure pressure spontaneous ignition would occur. These initial experiments were conducted with the downstream flow geometry shown in Figure 4, threaded into the exit of the straight through burst disk holder. The minimum internal exit diameter of the male Swagelok fitting is $0.472 \mathrm{~cm}\left(0.186^{\prime \prime}\right)$, and the overall length of the region from the plane of the burst disk to plane where area reduction occurs was $5.08 \mathrm{~cm}\left(2^{\prime \prime}\right)$.

Figure 5a documents a spontaneous ignition event and the ensuing turbulent jet flame established by the failure of a commercial burst disk at $43.04 \mathrm{~atm}$ pressure (618 psig). Though hydrogen combustion itself is almost non-luminous, small levels of impurities in the surrounding air and within the flow system cause the minimal luminosity observed in Figure 5a. Noise associated with burst disk failure and spontaneous ignition of the gases inside the downstream flow cavity was always substantially louder than the noise associated with a disk failure and no spontaneous ignition. The significantly louder noise is indicative of the spontaneous ignition process occurring inside the downstream flow configuration and likely results from deflagration/detonation transition in the flammable mixtures within the cavity. The ensuing stabilized turbulent jet diffusion flame downstream of the fittings also resulted in a distinct roaring sound not present with free-flowing, unignited hydrogen. Tests were repeated with the same configuration and commercial burst disks at failure pressures of 56.6, 42.5, and $22.1 \mathrm{~atm}$ (817, 610, and

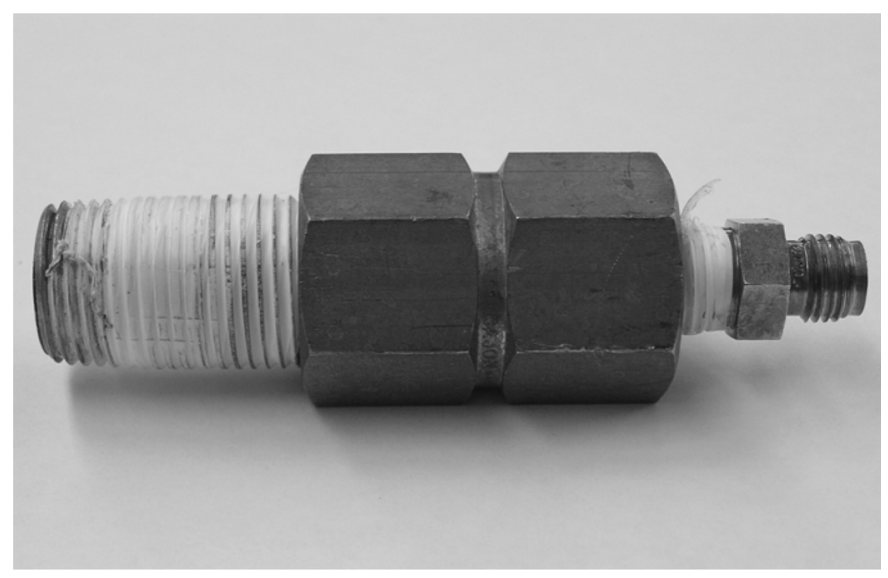

Figure 4. Downstream flow geometry used in initial experiments, composed of a $1 / 2^{\prime \prime}$ NPT pipe nipple $5.08 \mathrm{~cm}\left(2^{\prime \prime}\right)$ long, a $1 / 2^{\prime \prime}$ to $3 / 8^{\prime \prime}$ NPT female brass reducing union, and $3 / 8^{\prime \prime}$ NPT male to $1 / 4^{\prime \prime}$ male Swagelok tube reducer. 


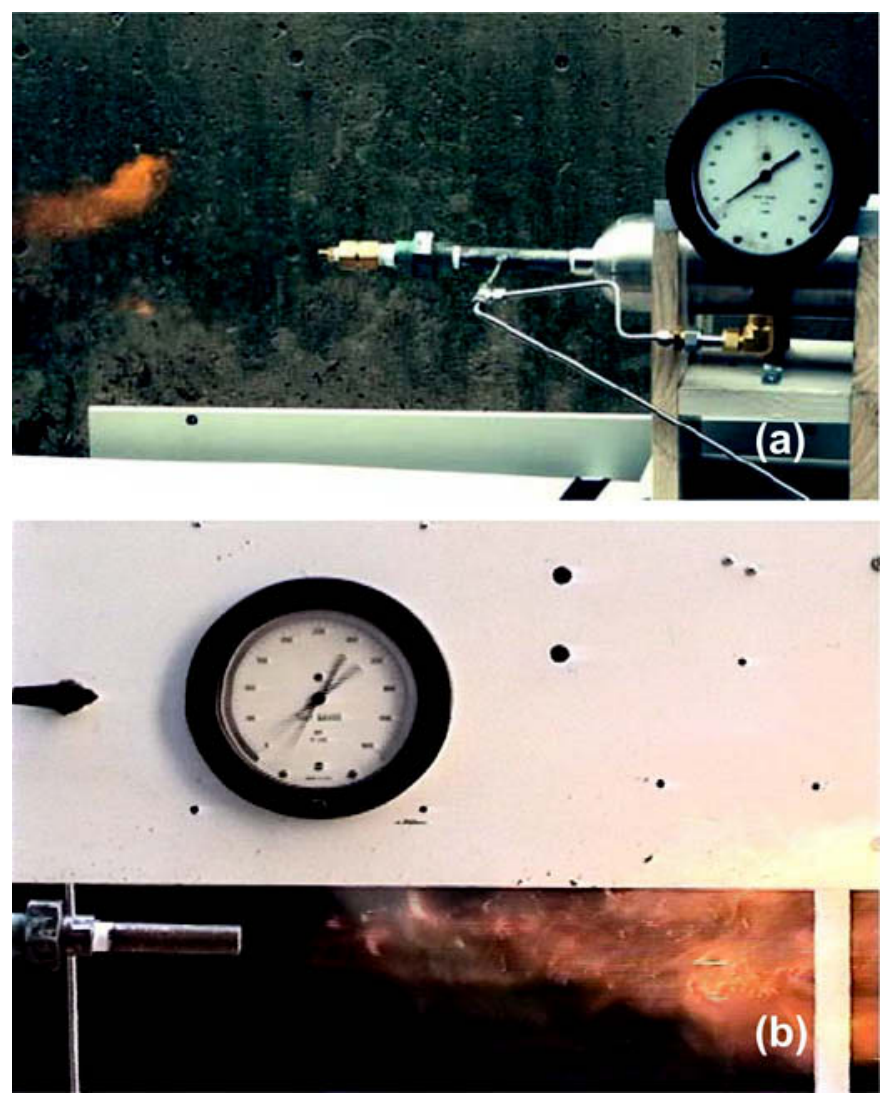

Figure 5. Sustained turbulent diffusion flame of hydrogen and air ignited by failure of a burst disk at (a) $43.1 \mathrm{~atm}$ (618 psig) using the downstream geometry shown in Figure 4 and (b) $86.1 \mathrm{~atm}(1250 \mathrm{psig})$ with a short length of unrestricted, constant diameter pipe $\left(12.7 \mathrm{~cm}, 5^{\prime \prime}\right)$.

310 psig), with identical results. No spontaneous ignition was observed with commercial burst disks designed to fail at $14.4 \mathrm{~atm}(197 \mathrm{psig})$.

On the expectation that a minimum failure pressure should exist below which no spontaneous ignition would occur, the test protocol using the configurations in Figures 4 and $5 \mathrm{a}$ was repeated with 15 different in-house manufactured burst disks designed with average failure pressures between $15.6 \mathrm{~atm}$ and $26.9 \mathrm{~atm}$ (215 to $380 \mathrm{psig}$ ). The failure pressure in each test was obtained from video records of the experiments, including the test pressure gage readings. Spontaneous ignition events were statistically distributed with a zero probability for failure pressures less than $20.4 \mathrm{~atm}$ (285 psig), and certain inflammation for 
failure pressures above $22.1 \mathrm{~atm}$ ( $310 \mathrm{psig}$ ). In addition to identifying a minimum pressure range below which no spontaneous ignition was observed, it was found that reducing the length of the $1 / 2^{\prime \prime}$ NPT pipe nipple to $3.81 \mathrm{~cm}\left(1.5^{\prime \prime}\right)$ led to no spontaneous ignition at all failure pressures even up to $56.6 \mathrm{~atm}$.

Modification of the flow geometry downstream of the $1 / 4^{\prime \prime}$ reducer tube exit also affected observations. For example, the addition of a straight section of $1 / 4^{\prime \prime}$ stainless steel tubing $(6.35 \mathrm{~mm}$ OD, $4 \mathrm{~mm}$ ID) downstream of the reducer fitting up to $46 \mathrm{~cm}$ long continued to result in inflammation for the same failure pressures without tubing. Addition of tube lengths greater than $300 \mathrm{~cm}$ suppressed inflammation altogether at failure pressures as high as $55.4 \mathrm{~atm}(800 \mathrm{psig})$. Apparently sufficient heat can be removed from gases ignited internally by the shock discharge leading to quenching before the inflamed volume can exit the tube.

In further experiments with reducer fittings that had internal exit diameters larger than that in Figure 5a, we found that the minimum pressure above which spontaneous ignition was observed increased. For example, for configurations with a reducer fitting $\left(1 / 2^{\prime \prime}\right.$ NPT male to $1 / 2^{\prime \prime}$ male tube) with an exit of $1.305 \mathrm{~cm}$ ID $\left(0.475^{\prime \prime}\right.$ ID), a minimum failure pressure of more than $67.3 \mathrm{~atm}$ ( $975 \mathrm{psig}$ ) was required to consistently produce spontaneous ignition. From such experiments and the simple theory discussed next, it was hypothesized that above some higher minimum disk failure pressure, spontaneous ignition might occur without any downstream fittings. Experiments were then conducted without any downstream geometry using the standard burst disk union flange (Figure la, Figure 1c). No spontaneous ignition events were observed for in-house manufactured disk failure pressures up to $113.2 \mathrm{~atm}$ (1650 psig). It was theorized that the transient mixing of expanding hydrogen with shocked hot air required to achieve spontaneous ignition is clearly related to mixing issues caused by transient flow conditions in the downstream pipe sections. As a result, a large number of experiments were performed using $1 / 2^{\prime \prime}$ NPT pipe $(1.27 \mathrm{~cm}$ ID) of different lengths $(3.81,4.54,12.7$, $15.24,25.4,30.48 \mathrm{~cm})$ and different disk failure pressures. In some of the tests the pipes were mated using $1 / 2^{\prime \prime}$ NPT female pipe unions $(1.83 \mathrm{~cm} \mathrm{ID)}$ to obtain longer lengths.

The overarching conclusion of these experiments was that achieving spontaneous ignition requires downstream geometry and failure pressure combinations that provide a critical level of sensible enthalpy in the shock heated air to cause autoignition of mixtures formed with hydrogen, as well as a critical volume of mixed material that is capable of undergoing flame spreading. For example, Figure $5 \mathrm{~b}$ shows a spontaneous ignition event observed with a disk failure pressure of $86.1 \mathrm{~atm}(1250 \mathrm{psig})$ for a constant cross-section $1 / 2^{\prime \prime}$ NPT exit pipe, $10.16 \mathrm{~cm}\left(4^{\prime \prime}\right)$ long. The overall cavity length from burst disk plane to the installed pipe exit 
was $12.7 \mathrm{~cm}\left(5^{\prime \prime}\right)$. For this disk failure pressure, spontaneous ignition was observed for downstream lengths up to $90 \mathrm{~cm}$, composed of $1 / 2^{\prime \prime}$ NPT stainless steel pipe section, each $30.5 \mathrm{~cm}\left(12^{\prime \prime}\right)$ in length, mated with $1 / 2^{\prime \prime}$ NPT female unions. No spontaneous ignition occurred in experiments with single pieces of pipe (i.e., no mating unions) with overall cavity lengths from burst disk plane to exit of less than $10.16 \mathrm{~cm}\left(4^{\prime \prime}\right)$. However, if shorter lengths of pipe were connected together with pipe unions to produce an overall length less than $10.16 \mathrm{~cm}$, spontaneous ignition resulted. Apparently, the internal diameter area change resulting from the presence of the $1 / 2^{\prime \prime}$ NPT union introduced the additional mixing necessary to achieve spontaneous ignition. These observations suggest that interactions of the core transient flow with the transient, developing boundary layer within the downstream geometry contribute significantly to achieving sufficient molecular mixing of expanding hydrogen and shocked air to cause spontaneous ignition. Even though the temperatures of mixed hydrogen and air may be high enough to achieve local ignition, a critical volume of flammable mixture must also exist in order to establish flame spreading and spontaneous ignition. Similar results were obtained for disk failure pressures of $99.6 \mathrm{~atm}$ and $113.2 \mathrm{~atm}$ (1450 and $1650 \mathrm{psig}$ ). The minimum constant area pipe length required to achieve ignition only slightly increased with increasing disk failure pressure, and did not decrease, as would be expected if the ignition phenomena was limited by chemical kinetic ignition delay time rather than mixing.

Finally, compressed methane release was tested in a cursory fashion under a number of configurations where experiments with hydrogen resulted in spontaneous ignition In these tests, $99.98 \%$ pure compressed methane was used with the knowledge that the ignition delay for methane/ air mixtures are typically equal to or longer than those for natural gas (methane that typically contains small amounts of higher hydrocarbons such as ethane, propane, and butane). No spontaneous ignition cases resulted for any configuration, with and without reducer exit fittings for failure pressures as high as $99.6 \mathrm{~atm}$ (1450 psig).

In summary, the experiments show that compressed hydrogen suddenly released into air by failure of a burst disk can produce spontaneous ignition if the burst disk failure pressure is sufficiently high, and the flow geometry after the burst disk results in sufficiently fast mixing of the escaping hydrogen and shocked air in contact with the expanding hydrogen. The range of failure pressures and geometries corresponding to spontaneous ignition events identify that reflected shock, shock-shock, and perhaps even shock focusing can be key in achieving sufficiently short chemical ignition delay times, while downstream geometry also contributes in enhanced mixing rates of shocked air and expanding hydrogen that produce sufficient volumes of flammable mixture in which 
an ignition kernel can result and propagate to establish a flame. At low compressed gas pressures, the chemical ignition time becomes the limiting factor, while at high compressed gas pressures, the mixing time of shocked air and expanding hydrogen to achieve significant volumes of flammable mixture becomes the limiting factor.

Downstream geometries that produce sufficient mixing and generate shock reflections can induce spontaneous ignition at lower compressed gas pressures, while at higher compressed gas pressures, transition of ignition to inflammation is primarily dependent on forming a critical ignition kernel that can spread a flame through the remaining flammable mixture. Boundary layer interactions of the expanding hydrogen inside the downstream pipe geometry appear to be important in achieving sufficient mixing of shock heated air and hydrogen in order to produce spontaneous ignition. Finally, by changes in downstream geometry alone, spontaneous ignition can be avoided altogether, even for high-pressure releases that clearly produce shock temperatures sufficient for autoignition to occur. The present observations cannot preclude that local autoignition might have occurred, but could not transition to turbulent diffusive burning.

The present experiments do not encompass the range of pressures under discussion for hydrogen storage (up to $\sim 681 \mathrm{~atm}$, i.e., $10,000 \mathrm{psi}$ ). Much more detailed experimental studies are needed to quantitatively determine the relative importance of different mixing mechanisms, shock-shock, and shock-focusing phenomena on producing spontaneous ignition. Future work should include much higher pressures, different failure diameters and down stream geometries, as well as consideration of boundary failures into open air along with shock interactions with surrounding obstructions in close proximity to the boundary failure.

Next, some simple theoretical arguments are offered to further support the experimentally observed spontaneous ignition events which are consistent with transient shock induced autoignition limited by local mixing phenomena between flammable and non-flammable materials, and to further extend to the observations reported with hydrogen to small molecule hydrocarbon discharges into air. Certainly, the observed spontaneous ignition dependencies on pressure and geometry as well as their reproducibility are inconsistent with electrostatic discharge or particle impact phenomena as ignition sources, frequently used to explain ignition of hydrogen releases into air. Some accidents and observed spontaneous ignition events may indeed be related to these mechanisms, but they are not the controlling phenomena in the present experiments. For reference, sample video records of some of the hydrogen spontaneous ignition tests described here are available on the web (Fuels and Combustion Research Laboratory, 2005). 


\section{SIMPLE TRANSIENT SHOCK THEORY AND IMPLICATIONS}

Hydrogen-oxygen combustion and explosion limits are a classic problem (Lewis and von Elbe, 1987). Historically, transient shock ignition phenomena have been utilized to generate conditions to study the ignition and combustion of homogenous premixed mixtures of gaseous fuels and oxidizers. Extensive literature exists on single pulse and reflected shock tube studies of premixed hydrogen-oxygen, methaneoxygen, and natural gas-oxygen mixtures (e.g., Eubank et al., 1981; Blumenthal et al., 1996; Huang et al., 2004). As noted earlier, much less work has addressed transient shock phenomena produced by compressed gas releases into air as a potential spontaneous ignition source. In this case, both the shock strength to produce sufficiently short ignition delays in mixed gases as well as sufficient mixing of shocked air and expanding flammable gas are required to achieve spontaneous ignition The mixing processes involved in the events observed above are limited by macroscopic mixing which enhances the interface between shock heated air and expanding hydrogen (well beyond that associated with the initial burst disk rupture) such that sufficient molecular mixing can occur.

While more complex numerical simulations of transient shock processes can be applied to this problem (e.g., Wang and Rehm, 2001; Liu et al., 2006), the pressures and temperatures produced by transient gas dynamic effects can be estimated using ideal shock equations (Ames Aeronautical Laboratory, 1953; Shapiro, 1954) to qualitatively estimate limiting chemical ignition times as a function of flammable gas and air properties (initial temperatures, pressures, flammable gas molecular weight).

Qualitatively, the conditions are shown at time $t_{1}$ in Figures 6 and 7. The pressure and temperature in region 2 behind the transient shock are strong functions of the speed of sound (i.e., molecular weight, temperature) of the compressed (flammable) driver gas relative to that of the driven gas (air), as well as the driver gas initial pressure in region $4, P_{4}$, in comparison to the pressure in region $1, P_{1}$. By proper selection of initial parameters and gas properties, temperatures and pressures created in region 2 can be sufficiently high to induce chemical reactions in mixed regions between the driver and driven gases (contact surface). Chemical reaction in the contact region requires both sufficient mixture temperatures to induce ignition as well as molecularly mixed regions containing both hydrogen and air. That flame propagation away from the ignition region should occur will require that these mixed regions lie within flammability limits and are of some critical volume that provides sufficient energy release to sustain flame propagation.

Setting aside the critical volume issue for the moment (assuming that mixing occurs sufficiently fast to result in mixtures that lie within 


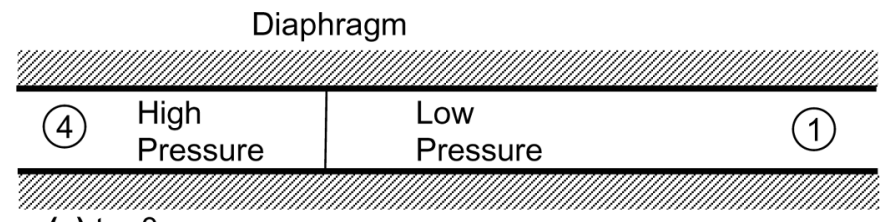

(a) $\mathrm{t}=0$

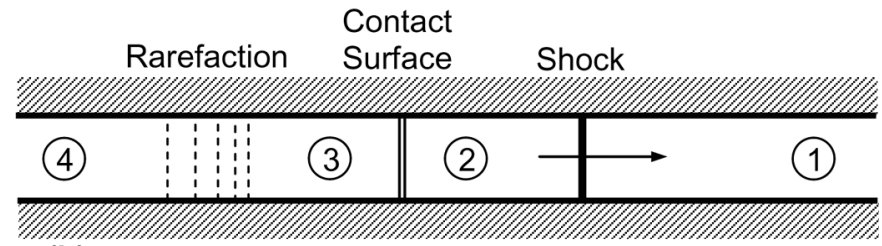

(b) $\mathrm{t}=\mathrm{t}_{1}$

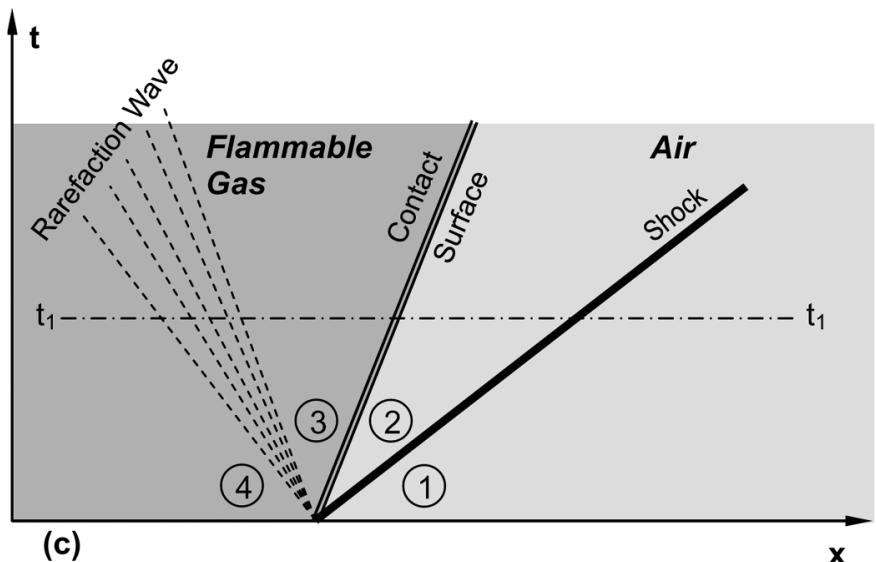

Figure 6. Schematic of classical single pulse shock tube operation. (a) Initial conditions; (b) time $t_{1}$, after fracture of diaphragm; (c) position of contact surface, shock as a function of time. (From Shapiro, 1954.)

flammability limits), 1-D shock analyses can be utilized to estimate spatial time scales based upon contact surface, shock velocities and cavity length from the burst disk to the exit plane used in the experiments. The chemical ignition time will be a function of the flammable gas and air concentrations in the mixture regions. The mixture region temperatures will be a function of the flammable gas properties, pressures $P_{4}$, $P_{1}$ and temperatures $T_{4}, T_{1}$. The local fluid temperatures in mixed regions can be no greater than the predicted $T_{2}$ and must be less as a result of mixing of the expanding (cooled) hydrogen with the shock-heated air. Qualitative estimates of mixture temperature can be generated by assuming that mixing (by whatever means) is instantaneous and 


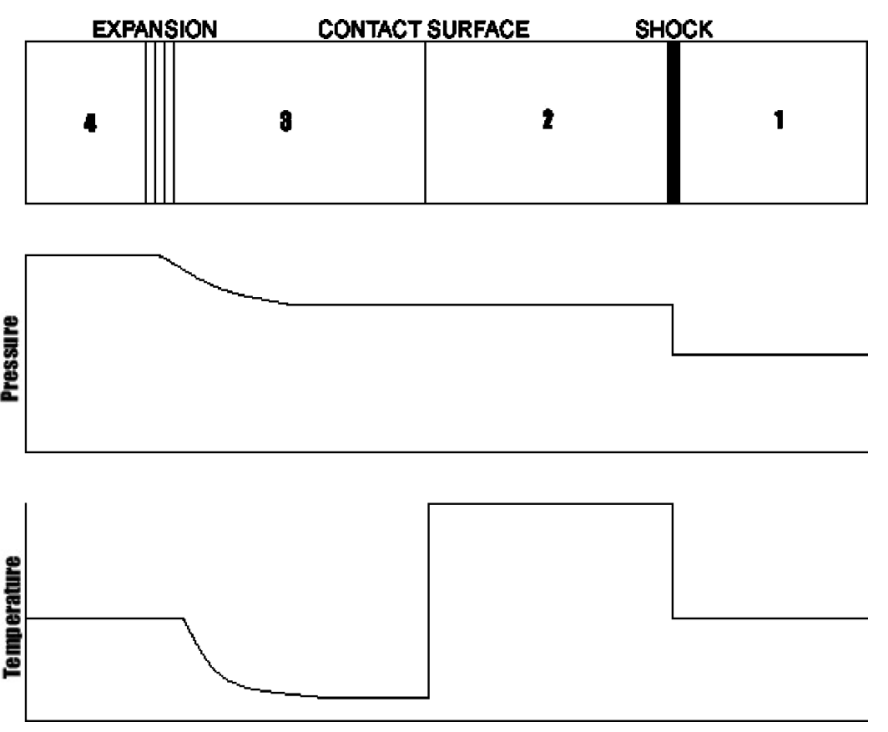

Figure 7. Pressure and temperature as a function of spatial location at time $t_{1}$ (Figure 7).

adiabatic. Assuming equal molar specific heats for hydrogen and air, the lean flammability limit mixture would be on the order of 30 to $50 \mathrm{~K}$ below $T_{2}$, and stoichiometric mixtures would be $240-450 \mathrm{~K}$ below $T_{2}$. Rich flammability limit mixtures would be the order of $600 \mathrm{~K}$ below $T_{2}$.

Using hydrogen as the driver gas and air as the driven gas, $T_{2}$ can be estimated as a function of $P_{4}$ from simple 1-D shock theory, yielding the results shown in Figure 8b. Using an available kinetic solver (Lutz et al., 1987), and a recent detailed chemical kinetics and thermochemistry model for hydrogen and oxygen developed in this laboratory ( $\mathrm{Li}$ et al., 2004), the ignition delay of premixed hydrogen-air mixtures at the lean and rich flammability and stoichiometric mixture conditions were calculated for the predicted $P_{2}$ and $T_{2}$ (Figure 8a). The calculations shown in Figure $8 \mathrm{a}$ were performed using a constant volume assumption with the chemical ignition delay time determined as the time to pressure rise. This is a common approach for calculating shock tube ignition delay times for premixed gas mixtures (Blumenthal et al., 1996). A constant pressure assumption and other criteria for defining ignition delay yield times of very similar magnitude. Also shown in the figure are the time scales for movement of the contact surface from the diaphragm rupture location by $1 \mathrm{~cm}$. The calculated ignition time corresponds more closely with ignition of mixtures near the lean flammability limit since the temperature for these mixtures differ only slightly from $T_{2}$, as pointed out previously. 

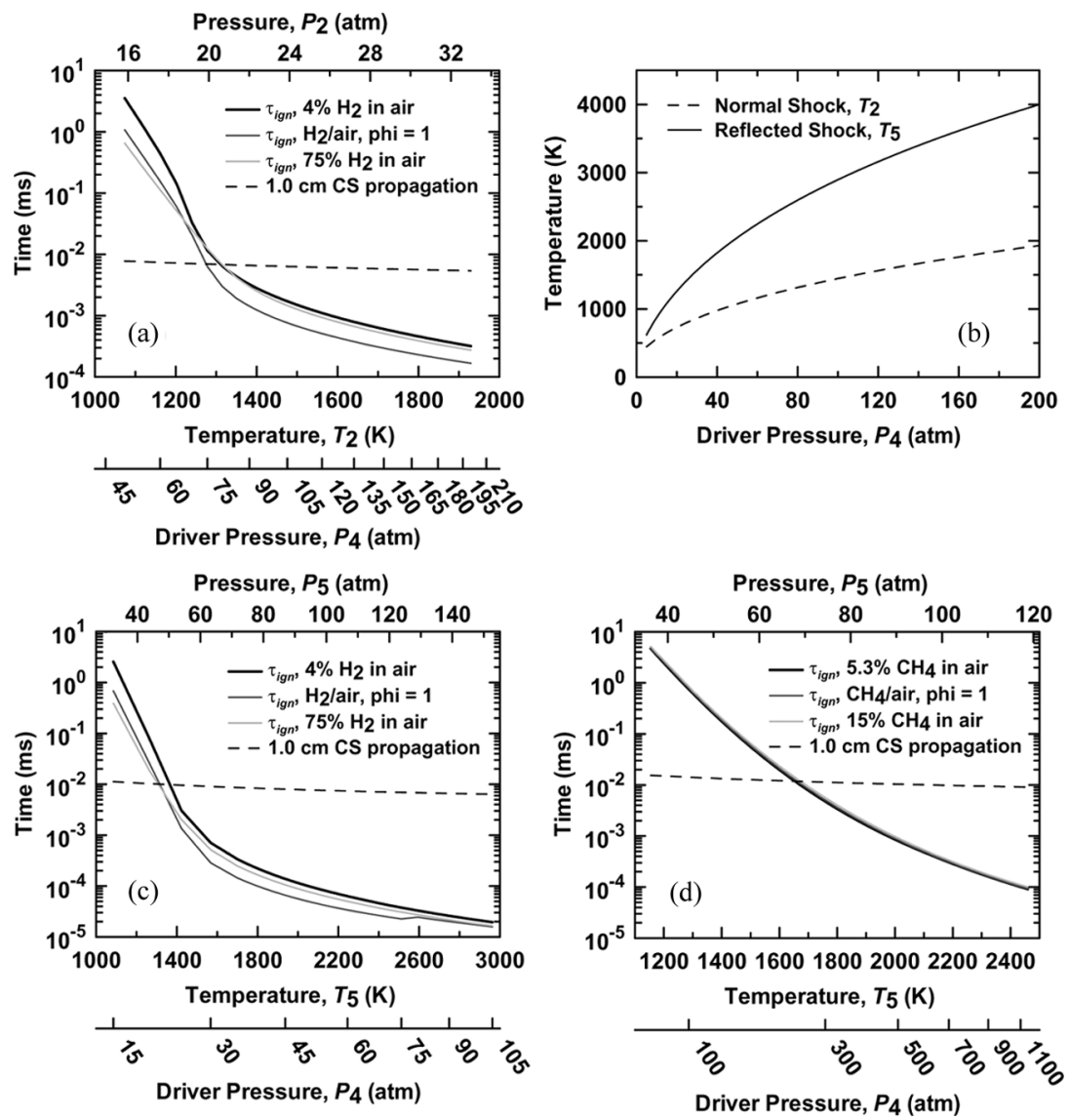

Figure 8. (a) Calculated hydrogen-air ignition delay times $\left(\tau_{\text {ign }}\right)$ for flammable mixtures at the temperature and pressure conditions behind an incident normal shock $\left(T_{2}\right.$ and $\left.P_{2}\right)$ associated with the driver pressure, $P_{4}$. The time scale for movement of the contact surface (CS) over a distance of $1 \mathrm{~cm}$ is also shown; (b) temperature behind incident and reflected shock waves $\left(T_{2}, T_{5}\right)$ as a function of driver gas pressure, $P_{4}$; driver gas, hydrogen; driven gas, atmospheric air; (c) ignition delays for flammable hydrogen-air mixtures at the reflected shock conditions of $T_{5}, P_{5}$ associated with the driver pressure, $P_{4}$ in (b); (d) Ignition delays for flammable methane-air mixtures at reflected shock conditions $\left(T_{5}, P_{5}\right)$.

One can immediately see from Figure 8a that $P_{2}$ and $T_{2}$ values associated with a driver pressure of $P_{4}=22.1$ atm ( 310 psig) cannot possibly explain the spontaneous ignition observed in the initial experiments with the smallest exit diameter and pipe length used (see Figure 4 and Figure 5a). Returning to the 1-D description of the problem, ignition times even at $T_{2}$ and $P_{2}$ are much longer than available time scales 
associated with the 1-D movement of the contact surface over the distance from where the burst disk is initially located to the reducer fitting, where the area change occurs in the tube internal diameter (Figure 4).

In the experiments, however, the reduction in tube cross-sectional area results in partial reflection from as well as transmission of the initial transient shock through the cross sectional area constriction. The result will be that local temperatures and pressures will be further increased ahead of the progressing initial contact surface by the partial reflection of the initial transient shock. As the constriction cross-sectional area approaches zero, the reflected shock effects will approach those commensurate with reflection of the transient shock from a tube end-wall, corresponding to the maximum pressure and temperatures that can be produced in the air ahead of the contact surface. The maximum reflected pressure and temperature $\left(P_{5}, T_{5}\right)$ can again be estimated using 1-D shock theory for a closed boundary configuration (Shapiro, 1954).

Figure $8 \mathrm{~b}$ compares the calculated $T_{2}$ and $T_{5}$ as functions of the hydrogen driver pressure, $P_{4}$. Because both pressure and temperature in the mixed regions can be increased as a result of shock reflection, ignition delay times will decrease significantly, as shown in Figure 8c, relative to those estimated based upon an initial shock transmission without reflection (Figure 8a). Ignition delays are reduced not only by the increased temperature, but also by the increased pressure due to shock reflection. The pressure and temperature conditions $\left(P_{5}, T_{5}\right)$ for a reflected normal shock corresponding to an initial driver pressure of $P_{4}=22.1 \mathrm{~atm}(310 \mathrm{psig})$ result in a chemical ignition delay estimate at least two to three orders of magnitude shorter than contact surface transit time (Figure 8c). This result can only mean that when spontaneous ignition was suppressed solely by shortening the distance from burst disk to the cross-sectional constriction, the limiting issue must have been that a critical volume of mixed flammable gases was not achieved in the physical time available for gas flow development in the region.

The actual pressures and temperatures generated by partial reflection decrease from those calculated with a closed-end boundary assumption $\left(P_{5}, T_{5}\right)$ as the reducer cross-sectional exit area is increased, eventually approaching the values produced by the initial transient shock $\left(P_{2}, T_{2}\right)$ for a constant diameter duct. As noted in the experiments, when reducers are present, the minimum pressure ratio for which spontaneous ignition will occur should increase as the ratio of the reducer cross-sectional exit area to the pipe cross sectional area is increased. At pressure ratios above about 85 , no reducer appears necessary to achieve mixture static temperatures and pressures sufficient to cause spontaneous ignition, provided a sufficient volume of flammable mixture is achieved in the hydrogen transit time within the downstream pipe length. 
Of course, the real processes that occur when the burst disk ruptures are multidimensional. The shock structures produced by the rupture are affected by both the initial geometry of the burst disk at failure (multidimensional) and the (stochastic) fracture geometry, producing shocksidewall and shock-shock interactions (Jiang et al., 1997). It is possible through such shock interactions and "shock focusing" (Fay and Lekawa, 1956; Gelfand et al., 2000; Bartenev et al., 2001) exist and produce higher local temperatures and pressures (and hence shorter ignition delays) than those estimated on the basis of simple 1-D theory. Moreover shock interactions with the side walls of the cavity will result in heating the air in the developing boundary layers near the walls and in increasing contact surfaces between the expanding hydrogen core and shock-heated air.

Returning now to the issue of mixing, in order for transient shock phenomena to produce the spontaneous ignition observed in the experiments, mixed regions of hot driven gas and expanding, cold hydrogen gas must reach temperatures sufficient to result in autoignition. Subsequent combustion was observed to transition from this partially premixed state to an external turbulent jet diffusion flame (Figure 5). What are the mechanisms that contribute to achieving sufficient mixing on the time scales of these events to result in the experimental observations? For all of the experiments conducted, the characteristic times for mixing are less than the order of $10^{-4} \mathrm{~s}$. Molecular diffusion across contact surfaces is orders of magnitude too slow to account for any significant formation of flammable mixture volumes, unless the overall interface area between expanding hydrogen and shocked air are increased by the developing flow conditions. Time scales associated with fluid dynamic instabilities at a 1-D contact surface (which could promote mixing) appear to be too long to be of relevance (Taylor, 1950; Brouillete, 2002) in terms of generating macroscopic mixing. However, recent studies of membrane failure show that the rupture itself of a planar diaphragm can produce significant turbulence and mixing at the subsequent contact surface (Erez et al., 2000). More importantly, multi-dimensional shock and contact surfaces can interact with the cavity sidewalls downstream of the burst disk failure, leading to turbulent mixing of shocked driven gas in the developing boundary layers at the pipe wall with driver gas in the core flow. Additionally, any change in pipe diameter (union fittings, reducer fittings) can lead to enhanced mixing. Which of these mechanisms are most important depends on the experimental configuration, but it is clear that interactions with the pipe boundary are important to observations. For example, spontaneous ignition occurred experimentally when using $1 / 2^{\prime \prime}$ NPT pipe lengths joined by NPT unions, however, for the same burst pressure, no spontaneous ignition resulted when using a straight $1 / 2^{\prime \prime}$ NPT pipe with the same length as the joined pipes. 
Figure 9 schematically describes the initial shock formation, turbulent mixing at the contact surface formed as a result of disk fracture, and the initial shock reflection at the cylindrical side walls downstream of the disk rupture location, resulting in reflected shock heating of the fuel/air mixtures formed in the contact region and at the cavity side walls. As noted above, reflective shock focusing effects may also be present near the axis of the flow, establishing even higher local temperatures and pressures. Even without considering shock focusing effects, however, the reflected shock conditions at hydrogen pressures above $22 \mathrm{~atm}$ are likely to result in chemical ignition delay times short enough to induce spontaneous ignition. Limited mixing of shocked air and hydrogen may still prohibit spontaneous ignition. Based on experimental results, above hydrogen pressures of approximately 86 atm and for downstream geometries without area changes, spontaneous ignition takes place as long as sufficient mixing is induced by downstream geometry.

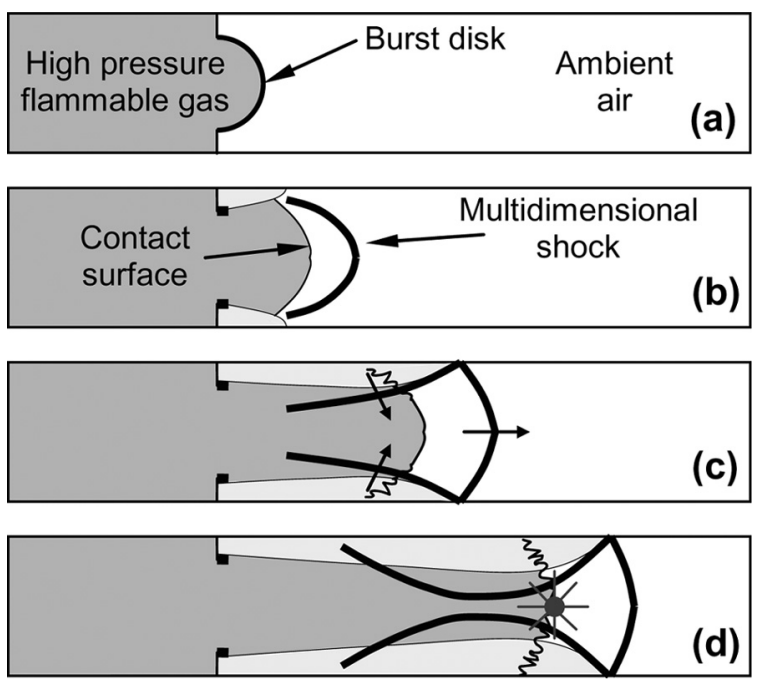

Figure 9. Schematic of the burst disk rupture process and mixing phenomena, (a) configuration prior to rupture; (b) initial multi-dimensional shock formation; (c) reflection from straight-through holder downstream cylindrical side wall. Interaction of reflected shock with contact surface enhances turbulent mixing and contributes to its further instability; (d) convergence of reflected shocks at the flow centerline increase pressure and temperature. The light grey shaded regions denote the growth of a boundary layer of hot air as the shock waves develop. The flammable gas/air mixtures generated at the boundary layer interface as well as at the contact surface lead to the experimentally observed ignition events. 
In work that was recently presented during the revision of this manuscript, Liu et al. (2006) describe a numerical simulation of hydrogen jetting from a high pressure tank. Direct numerical simulations in this work showed that for 40 and $70 \mathrm{MPa}$ compressed hydrogen expanding through a $1 \mathrm{~mm}$ hole, chemical ignition occurred at the interface between the expanding hydrogen and the air heated by the expanding hemispherical shock. However, no inflammation was observed because sufficient heat release was not available to overcome the cooling effects resulting from flow divergence. Essentially the numerically estimated mixing time scales were too long to produce a flammable mixture of critical volume. The results of this work suggest that compressed gas releases of hydrogen from unconfined planar surfaces are unlikely to produce spontaneous ignition, contrary to the observations reported for the present experiments that involve geometric constraints downstream of the point of pressure boundary failure. It is interesting to also note that the present observations are similar to the spontaneous ignition results obtained in the experiments of Chaineaux et al. (1990) described earlier. The present experiments not only confirm these results but show that imposition of a geometric constraint downstream of the pressure boundary failure location is critical to achieving spontaneous ignition. It is reasonable to speculate that other external geometries placed in the path of expanding spherical shocks might also lead to spontaneous ignition for planar pressure boundary failure conditions.

\section{SPONTANEOUS IGNITION OF NON-PREMIXED HYDROCARBON FUEL/AIR MIXTURES}

The strength of the initial transient shock generated by sudden boundary failure is a function of both $P_{4} / P_{1}$ and the molecular weight ratio of the driver and driven gases. Figure $8 \mathrm{~d}$ presents ignition delay times, based upon 1-D theory, as a function of reflected pressures and temperatures $\left(P_{5}, T_{5}\right)$ associated with the driver pressure, $P_{4}$, in the case of methane as the driver gas (large molecular weight). Note that the change in molecular weight of the driver gas substantially affects the calculated temperatures achievable for the same pressure. Using 1-D theory and methane as the driver gas, ignition delay times were calculated using the GRIMECH-3 mechanism for methane oxidation kinetics (Smith et al., 1999) as a function of compressed gas pressure. According to Figure 8d, spontaneous ignition should not be expected, and experiments confirm that even shock reflection and shock-shock interactions under the present configuration do not produce spontaneous ignition.

For experiments with pressures as high as $99.6 \mathrm{~atm}$ (1450 psig) and using the configuration of Figure 4, no clear visual sign of spontaneous 
ignition was observed. Moreover, turbulent free-jet diffusion flames could not be stabilized at steady flow exit conditions at the reducer fitting, even with piloted ignition. Considerably more experimental work will be necessary to establish if spontaneous ignition of natural gas mixtures with air can be induced by transient shock phenomena associated with pressure-boundary failure. This work is certainly warranted, given that storage and transmission pressures are likely to continue to increase. While simple theory and the potential for shock-shock interactions and shock focusing all suggest that this phenomenon has a finite probability for methane and natural gas, transition of ignition to flaming combustion of the continuing fuel jet will depend on the geometry envelope surrounding site of pressure release and bluff-body stabilization.

Using the simple 1-D shock calculation methods described here, Figure 10 presents pressures and temperatures for the initial transient shock $\left(P_{2}, T_{2}\right)$ and reflected shock $\left(P_{5}, T_{5}\right)$ for hydrogen- and methaneair systems compared with those using ethane or propane as the driver gas. The change in molecular weight of the driver gas from that of hydrogen to even that for methane has a very significant effect on the supply pressure, $P_{4}$, required to achieve values of $P_{5}$ and $T_{5}$ that lead to short chemical ignition delays comparable to time scales associated with shock and contact surface velocities and the length scales of downstream pipes and geometries investigated here. While it appears that ethane might be marginally capable of compression to values of $P_{4}$ sufficient to cause ignition and inflammation from shock reflections and focusing, liquefied gaseous fuels such as propane are not able to achieve the necessary gas phase driver pressures.

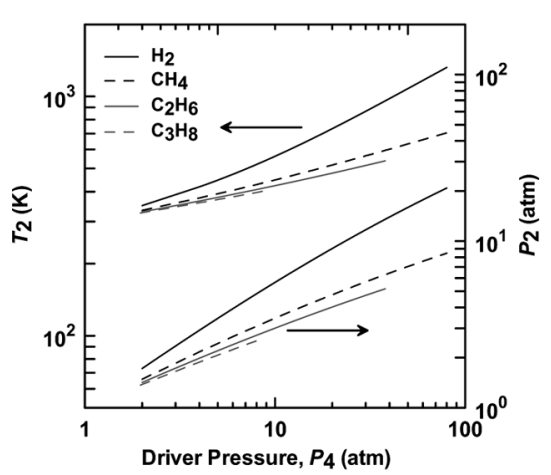

(a)

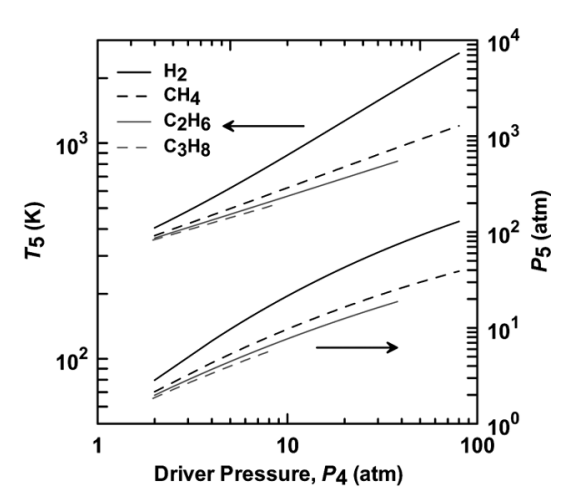

(b)

Figure 10. Calculated pressure and temperature as functions of driver gas species and pressure, $P_{4}$, (a) behind an incident shock $\left(P_{2}, T_{2}\right)$; (b) behind a reflected shock $\left(P_{5}, T_{5}\right)$. 


\section{CONCLUSION}

The present work conclusively establishes that within the storage and pipeline pressures used today and/or contemplated in the future for hydrogen, transient shock processes associated with rapid pressure boundary failure have the capacity to produce spontaneous ignition of the compressed flammable released into air, provided sufficient mixing is also present. Pressure boundary failure geometry, multi-dimensional shock-boundary, and shock-shock interactions in addition to molecular diffusion can provide the necessary short mixing time scales. Turbulent free jet hydrogen flames can be stabilized at sufficiently high jet velocities to result in continued combustion. Experimental observations identify that the minimum compressed gas pressure (relative to atmospheric pressure air) at which spontaneous ignition occurs is dictated by reflected shock and shock-shock interactions. The repeatable nature of the ignition and its characteristic time scale suggest that proposed ignition alternatives (e.g., electrostatic discharge) are not contributory to the present observations. Further experiments are needed to quantitatively define the experimental parameter ranges of gas temperature, pressure, pressure boundary thickness and structure, and pressure boundary local geometry that contribute to determining the envelope of design parameters over which shock induced inflammation will or will not result. These works need to include the analysis of external boundary failure and shock reflection from surrounding structures to encompass compressed pressure vessel and high pressure pipe failure modes inside enclosures. There is no doubt, however, that this phenomenon has been a cause of past fire incidents involving sudden releases of compressed hydrogen gas into air (e.g., National Research Council, 1995).

Simple 1-D shock calculations suggest that sudden compressed methane and natural gas discharges into air may cause similar reflected shock and focused shock-shock induced spontaneous ignition, but at considerably higher compression pressures (relative to hydrogen). It is unlikely that stabilized turbulent combustion of a gas jet will result for compressed hydrocarbon releases unless physical flame stabilization mechanisms (e.g., bluff-body stabilization) are present. The molecular weight (relative to air components) and/or the liquefaction pressure of the fuel preclude transient shock induced spontaneous ignition of other compressed hydrocarbon gases. To date, it appears that this phenomenon has escaped consideration in the analysis of most accidental fires and in the development of piping and storage safety codes both for hydrogen and natural gas.

Moreover, an important observation is that downstream flow geometry or objects in the path of exiting jets formed by the sudden discharge of compressed flammable gases into air have impact on whether 
shock induced spontaneous ignition. Methodologies to enhance or mitigate continued combustion likely exist and such options need to be identified and characterized by more detailed measurements so that safe storage and distribution systems can be interfaced with general consumer use of compressed hydrogen.

\section{REFERENCES}

Alcock, J.L., Shirvill, L.C., and Cracknell, R.F. (2001) Compilation of Existing Safety Data on Hydrogen and Comparative Fuels. Report EIHP 2, Fifth Framework Programme (1998-2002), Shell Global Solutions.

Alpert, J.Y. and Homer, C.J. (2005) Shock Induced Auto-Ignition of Previously Unmixed Hydrogen/Air Mixtures. Undergraduate Senior Thesis, Mechanical and Aerospace Engineering, Princeton University, Princeton, NJ.

Ames Aeronautical Laboratory (1953) Equations, Tables, and Charts for Compressible Flow. Report 1135, Ames Aeronautical Laboratory, Moffett Field, CA.

Argonne National Laboratory (2004) Basic Research Needs for the Hydrogen Economy. Report on the Basic Energy Sciences Workshop on hydrogen production, storage, and use, U.S. Department of Energy, Washington, DC. [Online] Available: http://www.sc.doe.gov/bes/reports/files/NHE_rpt.pdf [1 July 2005].

Astbury, G.R. and Hawksworth, S.J. (2005) Spontaneous ignition of hydrogen leaks: a review of postulated mechanisms. International Conference on Hydrogen Safety, Pisa, Italy.

Bartenev, A.M., Komik, S.V., Gelfand, B.E., Gronig, H., and Oliver, H. (2001) Effect of reflection type on detonation initiation at shock-wave focusing. Shock Waves, 10, 205-215.

Berman, M. (1986) A critical review of recent large-scale experiments on hydrogen/air detonations. Nucl. Sci. Eng., 93, 321-347.

Blumenthal, R., Fieweger, K., Komp, K.H., and Adomeit, G. (1996) Gas dynamic features of self ignition of non diluted fuel/air mixtures at high pressure. Combust. Sci. Technol., 113, 137-166.

Bond, J. (1991) Sources of Ignition: Flammability Characteristics of Chemicals and Products, Butterworths-Heinemann Ltd., Oxford, p. 52.

Brouillette, M. (2002) The Richtmyer-Meshkov instability. Annu. Rev. Fluid Mech, 34, 445-468.

California Hydrogen Highway (2004) Hydrogen Use and Safety [Online]. Available: http://www.hydrogenhighway.ca.gov/hysafety/hysafety.htm [18 May 2005].

Chaineaux, G., Mavrothalassitis, G., and Pineau, J. (1990) Modelization and validation tests of the discharge in air of a vessel pressurized by a flammable gas. In Kuhl, A.L., et al. (Eds.) Dynamics of Detonations and Explosions: Explosion Phenomena, Prog. Astronaut. Aeronaut., Vol. 134, pp. 104-137

Compressed Gas Association (2004) Hydrogen Vent Systems, 2nd ed. CGA G-5.5. Edeskuty, F.J. and Stewart, W.F. (1996) Safety in the Handling of Cryogenic Fluids. Plenum Publishing Corporation, New York, Chapter 7. 
Erez, L., Sadot, O., Oron, D., Erez, G., Levin, L.A., Sharvts, D., and Ben-Dor, G. (2000) Study of the membrane effect on turbulent mixing measurements in shock tubes. Shock Waves, 10, 241-251.

Eubank, C.S., Rabinowitz, M.J., Gardiner, W.C. Jr., and Zellner, R.E. (1981) Shock-Initiated Ignition of Natural Gas-Air Mixtures. Proc. Combust. Instit., 18, 1767-1774.

Fay, J.A. and Lekawa, E. (1956) Ignition of combustible gases by converging shock waves. J. Appl. Phys., 27, 261-266.

Fischer, M. (1986) Safety aspects of hydrogen combustion in hydrogen energy systems. Int. J. Hydrogen Energ., 11, 593-601.

Fuels and Combustion Research Laboratory (2005) [Online]. Available: http:// www.princeton.edu/ combust/ [5 August 2005].

Gelfand, B.E., Komik, S.V., Bartenev, A.M., Medvedev, S.P., Gronig, H, and Olivier, H. (2000) Detonation and deflagration initiation at the focusing of shock waves in combustible gas mixtures. Shock Waves, 10, 197-204.

Gregory, D.P. and Pangborn, J.B. (1976) Hydrogen energy. Annu. Rev. Energy, 1, 279-310.

Hord, J. (1978) Is hydrogen a safe fuel? Int. J. Hydrogen Energ., 3, 157-176.

Houf, W.G. and Schefer, R.W. (2004) Determination of separation distances from large-scale hydrogen releases. International Code Council (ICC) Hydrogen Ad Hoc Committee Meeting, Coral Gables, FL.

Huang, J, Hill, P.G., Bushe, W.K., and Munshi, S.R. (2004) Shock-tube study of methane ignition under engine-relevant conditions: experiments and modeling. Combust. Flame, 136, 25-42.

INGAA Foundation (2004) An updated assessment of pipeline and storage infrastructure for the North American gas market: adverse consequences of delays in the construction of natural gas infrastructure. Report F-2004-01, Energy and Environmental Analysis, Inc., Arlington, VA.

Jiang, Z., Takayama, K., Babinsky, H., and Meguro, T. (1997) Transient shock wave flows in tubes with a sudden change in cross section. Shock Waves, 7, 151-162.

Kaltayev, A., Leblanc, J.E., and Fujiwara, T. (1999) Influence of turbulence on the deflagration to detonation transition in a tube. Proceedings from the 17th International Colloquium on the Dynamics of Explosions and Reactive Systems, Heidelberg, Germany.

Kruse, B., Grinna, S., and Buch, C. (2002) Hydrogen-Status and Possibilities. [Online]. Available: http://www.bellona.no/data/f/0/26/97/0 9811 1/Hydrogen 6-2002.pdf [15 May 2005].

Lewis, B. and von Elbe, G. (1987) Combustion Flames and Explosions of Gases. Academic Press, New York.

Li, J., Zhao, Z., Kazakov, A., and Dryer, F.L. (2004) An updated comprehensive kinetic model of hydrogen combustion. Int. J. Chem. Kinet., 36, 566-575.

Liñán, A. and Crespo, A. (1976) An asymptotic analysis of unsteady diffusion flames for large activation energies. Combust. Sci. Tech., 14, 95-117.

Liu, Y.-F., Sato, H., Tsuboi, N., Hjigashino, F., and Hayashi, A.K. (2006) Numerical simulation on hydrogen fuel jetting from high pressure tank. Sci. Tech. Energ. Mater., 67, 7-11. 
Lutz, A.E., Kee, R.J., and Miller, J.A. (1987) SENKIN: a Fortran program for predicting homogeneous gas phase chemical kinetics with sensitivity analysis, Report SAND87-8248, Sandia National Laboratories, Albuquerque, NM.

National Hydrogen Association (2005) Hydrogen fact sheet 1.008. [Online]. Available: http://www.hydrogenassociation.org/H2-Safety-Fact-Sheet.pdf [13 April 2005].

National Hydrogen and Fuel Cell Codes and Standards Coordinating Committee (2005). [Online] Available: http://www.hydrogenandfuelcellsafety.info/ [20 September 2005].

National Research Council (1995) Prudent Practices in the Laboratory: Handling and Disposal of Chemicals. National Academy Press, Washington, DC, p. 123.

NaturalGas.org. (2004) The Transportation of Natural Gas. [Online]. Available: http://www.natural gas.org/naturalgas/transport.asp [14 July 2005].

NFPA (2005) NFPA 55: Standard for Storage, Use, and Handling of Compressed Gases and Cryogenic Fluids in Portable and Stationary Containers, Cylinders, and Tanks. National Fire Protection Association, Quincy, MA.

NFPA. Hydrogen Safety Symposium 2005. NFPA World Safety Conference \& Exposition, Mandalay Bay Resort \& Convention Center Las Vegas, NV, June 6-7, 2005.

Rifkin, J. (2002) The Hydrogen Economy, Penguin Putnam Inc., New York.

Schefer, R.W., Houf, W.G., Bourne, B., and Colton, J. (2004) Turbulent hydrogen-jet flame characterization. Int. J. Hydrogen Energ., submitted.

Schefer, R.W., Houf, W.G., Moen, C.D., Chan, J.P., Maness, M.A., Keller, J.O., Leon, M.V. and Tarn, R. (2004) Hydrogen Codes and Standards Unintended Release Workshop. Sandia National Laboratories, Livermore, CA.

Shapiro, A.H. (1954) The Dynamics and Thermodynamics of Compressible Fluid Flow. The Ronald Press Company, New York.

Shinnar, R. (2003) The hydrogen economy, fuel cells and electric cars. Technol. Soc., 25, 455-476.

Sidorov, V.P. and Dorofeev, S.B. (1998) Influence of initial temperature, dilution and scale on DDT conditions in hydrogen-air mixtures. Arch. Combust., 18, 87-103.

Smith, G.P., Golden, D.M., Frenklach, M., Eiteneer, B., Goldenberg, M., Bowman, C.T., Hanson, R.K., Song, S., Gardiner Jr., W.C., Lissianski, V.V., and Qin, Z. (1999) GPJ-MECH 3.0. [Online]. Available: http://www. me.berkeley.edu/gri_mech/ [2 February 2005].

Swain, M. (2004) Hydrogen Properties Testing and Verification. Hydrogen and Fuel Cells Summit VIII, Miami, FL.

Taylor, G.I. (1950) The instability of liquid surfaces when accelerated in a direction perpendicular to their planes. Proc. R. Soc. A, 201, 192-196.

Thomas, E. (1997) Direct-Hydrogen-Fueled Proton-Exchange-Membrane Fuel Cell System for Transportation Applications: Hydrogen Vehicle Safety Report. DOE report DOE/CE/50389-502, Ford Motor Co., Dearborn, MI.

Transport Canada Prairie and Northern Region (2003) Arctic gas pipeline construction impacts on northern transportation. [Online]. Available: http:// www.arcticgaspipeline.com/Reference/Documents\&Presentations/Canada/ 1-03ArcticGasPipelineConstructionSTUDY.pdf [21 June 2005]. 
Vidicom Media Productions (2005) The Hindenberg. [Online]. Available: http:// www.vidicom-tv.com/hindenburg/index.htm [18 May 2005].

Wang, B.L. and Rehm, W. (2001) Numerical studies of shock reflection and ignition. Proceedings from the 18th International Colloquium on the Dynamics of Explosions and Reactive Systems, Seattle, WA.

Wolanski, P. and Wojcicki, S. (1972) Investigation into the Mechanism of the Diffusion Ignition of a Combustible Gas Flowing into an Oxidizing Atmosphere. Proc. Combust. Instit., 14, 1217-1223.

Zuttel, A. (2003) Materials for hydrogen storage. Mater. Today, 6, 24-33. 